\title{
Sacrifícios, sonhos, indústria cultural: retratos da educação do corpo no esporte escolar
}

\author{
Danielle Torri \\ Beatriz Staimbach Albino \\ Alexandre Fernandez Vaz \\ Universidade Federal de Santa Catarina
}

Correspondência:

Alexandre Fernandez Vaz

Núcleo de Estudos/Pesq.Educação

e Sociedade Contemporânea

MEN/CED/UFSC - CP 476

Campus Universitário (Trindade)

88040-900 - Florianópolis - SC

e-mail: alexfvaz@pq.cnpq.br

\section{Resumo}

0 artigo apresenta resultados de uma pesquisa que procurou investigar aspectos da educação do corpo, focando um programa de Esporte Escolar para meninos e meninas de uma escola pública de Florianópolis. Foram realizadas observações sistemáticas do contexto das sessões de treinamento e das competições, além de entrevistas narrativas e levantamento de alguns dados da instituição. Os resultados foram organizados em três grandes categorias de análise. Nomeamos a primeira de Castigos, punições e sacrifícios. Ela diz respeito à forma encontrada pelos treinadores para lidar com a dinâmica de repreensão e emulação de sua equipe. A segunda categoria, batizada de Formação humana $X$ sonho de profissionalização, discorre sobre o papel das representações e expectativas sobre o futebol para as crianças em contraposição à formação que a escola e o esporte prometem lhes proporcionar. A escolha da terceira categoria se deu pela presença constante dos rituais nas práticas corporais organizadas, com especial atenção, nesse caso, ao esporte. Ela foi denominada Rituais como técnica. As considerações finais sugerem uma interpenetração entre rituais, expectativas de futuro e questões moralistas envolvidas no esporte, apontando a prevalência do interesse de controle como central. Além disso, sugerem o mimetismo das práticas do esporte convencional pela mediação da indústria cultural.

\section{Palavras-chave}

Educação do corpo - Indústria cultural - Teoria crítica e Educação

- Esporte escolar - Educação Física Escolar.
" 0 texto apresenta parte dos resultados do projeto integrado Teoria Crítica, racionalidades e Educação, financiado pelo CNPq (Bolsas PIBIC, Auxílio Pesquisa, Bolsa de Produtividade em Pesquisa), FAPESC (Auxílio Pesquisa) e UFSC (Bolsas PIBIC, Programa Funpesquisa). 


\section{Sacrifices, dreams, culture industry: portraits of bodily education in school sports*}

Danielle Torri

Beatriz Staimbach Albino

Alexandre Fernandez Vaz

Universidade Federal de Santa Catarina

Contact:

Alexandre Fernandez Vaz

Núcleo de Estudos/Pesq.Educação

e Sociedade Contemporânea

MEN/CED/UFSC - CP 476

Campus Universitário (Trindade)

88040-900 - Florianópolis - SC

e-mail: alexfvaz@pq.cnpq.br

\begin{abstract}
This article presents results of a research that sought to investigate aspects of bodily education, focusing in a program of School Sports for boys and girls from a public school in Florianópolis, Brazil. Systematic observations were made of the contexts of training sessions and competitions, apart from discursive interviews and some data gathering about the institution. Results were organized in three major analysis categories. The first of them was called Punishments, penalties and sacrifices. It relates to the way found by coaches to deal with the dynamics of reprehension and encouragement of their teams. The second category, entitled Human formation versus The dream of professionalization, describes the role of representations and expectations about football (soccer) for children, in contrast to the formation that school and sport promise to afford them. The choice of the third category was a consequence of the constant presence of rituals in the organized bodily practices, with special attention here to sport. It was denominated Rituals as technique. The final considerations of the article suggest an interpenetration of rituals, future expectations and moralist questions involved in sport, pointing to the prevalence of interests of control. Additionally, they suggest the mimetism of the conventional sport practices with the mediation of the culture industry.
\end{abstract}

\section{Keywords}

Bodily education - Culture industry - Critical theory and sport School sports - School physical education.

\footnotetext{
"The text presents part of the results of the Integrated Project Critical Theory, Rationalities and Education, sponsored by CNPq (PIBIC scholarships, Research Grant, Productivity in Research scholarship), FAPESC (Research Grant) and UFSC (PIBIC scholarships, Funpesquisa Program). The authors wish to thank the referees from Research and Education for their encouragement and the suggestions offered to the first version of this article.
} 


\section{Introdução'}

0 esporte é tradicionalmente uma atividade considerada positiva na educação de crianças e jovens e sua presença nos estabelecimentos formais de ensino, assim como em projetos que procuram a inclusão social, é bastante conhecida e pouco questionada. Disciplina, solidariedade e aprendizado com as derrotas são valores sempre lembrados para destacar a importância das práticas esportivas na formação de crianças e jovens.

Um dos espaços privilegiados de realização do esporte são as aulas de Educação Física. Parte dos programas e currículos escolares formais, as aulas dessa disciplina encontram no esporte, via de regra, sua realização mais freqüente, mesmo que sejam elas, muitas vezes, uma caricatura do esporte formal, dadas as condições materiais precárias de nossas escolas.

Um outro modelo da presença do esporte nos ambientes escolares é o Esporte Escolar, oferecido a crianças e jovens por meio de aprendizagem e treinamento sistemáticos de uma ou mais modalidades esportivas, inclusive com a pretensão de desempenho em competições. Trata-se de projeto em correspondência e/ou concorrência com a Educação Física Escolar, conforme as dimensões que a disciplina encontra na escola e de acordo com a carga simbólica que o esporte carrega - freqüentemente ele é, na cultura escolar, considerado mais organizado e atraente, destinado aos "melhores" e "mais talentosos" alunos (Bassani; Torri; Vaz, 2003).

0 objetivo deste artigo é apresentar resultados de uma pesquisa que procurou analisar aspectos de um programa de Esporte Escolar de uma escola da região central de Florianópolis, Santa Catarina. Trata-se de uma grande instituição pública com departamento específico para o trato do Esporte Escolar e com um clube associado a ele que leva o nome da instituição. A prática desse programa substitui a obrigatoriedade da Educação Física.

Inspiramo-nos em nossa pesquisa na crítica à indústria cultural, conceito crítico e irônico apresentado por Theodor W. Adorno e
Max Horkheimer (1997) e desenvolvido principalmente pelo primeiro (Adorno, 1997a, entre tantos outros trabalhos) e por toda uma tradição que o tem sucedido. A fecundidade do conceito, cuja radicação é o projeto de crítica à racionalidade instrumental proposto nos fragmentos filosóficos de Dialética do esclarecimento, apresenta-se tanto porque remete à produção e reprodução da cultura sob forma de mercadoria, quanto porque indica a forja de subjetividades sob o comando dessa ordem. Exemplo desse processo é a presença notável do esporte tal como é produzido em sua condição de espetáculo que passa, por sua vez, a ser a referência primeira para as aulas de Educação Física Escolar.

É na escola que as culturas de uma sociedade, de forma dinâmica, se reforçam - ainda que eventualmente se fragmentem -, não deixando escapar o corpo de forma ilesa. Dito de outra forma, a escola, por meio da Educação Física, mas não somente dela, absorve, interpreta e trabalha concepções e práticas corporais presentes em outros tempos e espaços da sociedade. No ambiente em questão, o corpo não está exposto somente nas aulas de Educação Física e no programa de Esporte Escolar. Ele está presente nas aulas de Ciências e de Biologia que têm no corpo humano um dos conteúdos principais, mas não somente no que diz respeito à grade curricular, e sim por vezes em atividades extraclasses, como palestras e seminários que se ocupam em discorrer sobre inúmeros temas relacionados àquele. lsso ocorre, na instituição, freqüentemente a partir de solicitação dos pais ou dos próprios alunos como, por exemplo, no sempre valorizado tema da sexualidade.

A escolha do grupo pesquisado, a ser logo abaixo detalhado, se deu em função dos resultados da investigação de Bassani, Torri e Vaz (2003) que tratou de um grupo de esporte escolar de faixa etária imediatamente inferi-

1. Agradecemos aos pareceristas da Revista Pesquisa e Educação pelas palavras encorajadoras e sugestões apresentadas à primeira versão do artigo. 
or àquela que pesquisamos e da ampliação do foco para um grupo feminino. Segundo esses autores, haveria uma ambigüidade no Esporte Escolar, manifesta na oscilação entre uma conformação pedagógica que ensina a perseguir, antes de tudo, a vitória, e outra, de caráter pretensamente formativo, que acentuaria os valores do esporte, algo presente no discurso (oscilante) do treinador, das mães e dos pais dos alunos. Trabalhávamos com a hipótese de que, com o avanço da idade, o caráter agonístico se acentuaria, o que, de fato, parece ser verdadeiro. Procuramos ter o grupo feminino como uma baliza comparativa, algo que se tornou bastante útil para o trabalho, sobretudo ao identificarmos as práticas masculinas como modelo esportivo idealizado, tanto no que se refere ao padrão técnico a ser alcançado, quanto no que diz respeito à educação para a dureza.

Nas páginas a seguir, expomos brevemente algumas questões teórico-metodológicas que nortearam a realização da pesquisa, destacando, sobretudo, os procedimentos para coleta e análise dos dados, para logo então apresentar os principais resultados e conclusões por nós alcançados.

\section{Da centralidade do corpo - algumas questões metodológicas}

0 corpo é, nos tempos contemporâneos, definidor de condutas e de normas, portador de valores, suporte e disseminador de signos, mensageiro de significados que provoca, simultaneamente, admiração e repulsa. Ele é resultado do cruzamento entre natureza e cultura e, como tal, passa por processos de incitamento e potencialização para fins específicos de controle nos ambientes educacionais.

Enquanto há uma educação do corpo em todos os espaços e tempos sociais - conformando mesmo, em algumas circunstâncias, pedagogias corporais -, é na escola que isso se cristaliza de forma ímpar. Isso não acontece apenas nas aulas de Educação Física, discipli- na que de modo mais explícito toma o corpo como objeto. Ele é, sobretudo, educado na sala de aula, pelas outras disciplinas que tratam diretamente ou não de questões relacionadas a ele (como Ciências e Religião), e pelas restrições impostas por suas disposições no espaço, pelas regras implícitas ou explícitas - quando e como se pode levantar da carteira, sair da sala, beber água, ir ao banheiro, ser vítima de punições etc. Em uma palavra, alunos e professores são catequizados pelos castigos, pelos interditos, pelos hábitos alimentares, pelos cuidados com seu corpo e com os dos outros nos corredores, nos portões, nas carteiras e nas quadras.

Nesse quadro, deparamo-nos com outro elemento educador e civilizador do corpo nos ambientes educacionais: o esporte. Se ele tem na escola importância destacada é porque se apresenta, como poucos outros fenômenos, como definidor de sucesso, de superação, de beleza e, segundo alguns, como Welsch (2001), até mesmo como expressão de arte. Há um enorme reforço para que ele seja, freqüentemente, o elemento central das aulas e o conteúdo principal das práticas na Educação Física.

O campo investigado foi, como dito, um grande colégio público da região central de Florianópolis que dispõe, no que se refere aos espaços diretamente ligados às práticas corporais, de condições materiais distintivas: quadras poliesportivas, materiais diversos, ginásio coberto, sala de danças e artes marciais. Também se diferencia por possuir dois departamentos que estão diretamente vinculados à educação do corpo: 0 Departamento de Educação Física e o Departamento de Esporte Escolar, este tratando de promover o aprendizado de modalidades esportivas e o treinamento para competições federativas oficiais, possibilitando aos alunos a substituição das aulas de Educação Física curricular obrigatórias pela prática do treinamento esportivo.

Observamos, orientados por um roteiro específico, duas turmas/equipes de futsal. Trata-se da modalidade que sucede o antigo futebol de salão, reconhecida e oficializada pela FIFA (Federação Internacional de Futebol), 
órgão que administra o futebol. Embora com estatuto próprio, o futsal ainda é visto como uma escola para o futebol, fato reforçado pelo número expressivo de destacados jogadores com sucesso no campo que, quando crianças ou jovens, freqüentaram a quadra. Essa mesma expectativa não é confirmada pelos atletas já formados e com grande desempenho no futsal, que não encontram o mesmo sucesso no campo.

A primeira turma observada era da categoria infantil masculina, na qual treinavam crianças de 12 a 14 anos. Esses treinamentos aconteciam à noite, todos os dias da semana, durante hora e meia. Um professor ligado ao Departamento de Esporte Escolar era o treinador do grupo ${ }^{2}$. Acompanhamos quinze sessões de treinamento da equipe, durante sete semanas. Nesse período, também observamos três partidas pelos campeonatos municipal e estadual. 0 segundo grupo escolhido foi uma turma/ equipe feminina de faixa etária superior à masculina que participava das atividades esportivas em substituição às aulas regulares de Educação Física no Ensino Médio. Elas treinavam três vezes na semana, por hora e meia no período da tarde, treinadas também por um professor pertencente ao Departamento de Esporte Escolar. Observamos oito sessões de treinamento dessa equipe, durante três semanas, e também assistimos a uma partida do campeonato estadual de futsal em que tomaram parte. Foram também realizadas entrevistas narrativas com alguns alunos e com os professores das turmas observadas.

Saliente-se que nossas observações não se restringiram apenas aos momentos de treinamento propriamente dito, mas também a muito do entorno e das situações que permeavam o contexto observado. A atuação dos pais dos atletas, ao assistirem aos treinamentos ou torcerem por seus filhos e filhas nas partidas, enriqueceram nossos dados. Também momentos que antecediam os treinamentos ou os jogos, em que tivemos a oportunidade de observar e conversar com as crianças e jovens, ajudaram-nos a formular e repensar algumas questões, assim como as entrevistas que realizamos com jogadores e técnicos.
Durante o acompanhamento das sessões, o treinamento dos meninos teve uma pausa de três semanas em função do recesso escolar entre os semestres letivos e de uma reforma no ginásio coberto. Esse último fator atrapalhou muito o trabalho do técnico, que em função do clima - frio, impedindo atividades externas - ou dos espaços ocupados por outras modalidades, não conseguia treinar sua equipe da forma como julgava conveniente. Isso fez com que ele freqüentemente conduzisse o grupo para praticar em outros lugares, fora da escola, o que dificultou, por vezes, também nossas observações.

Os resultados foram analisados qualitativamente. Formulamos as categorias de análise cruzando os objetivos da pesquisa e as expressões do objeto investigado. Uma premissa foi considerada em todo o transcorrer da investigação e se refere ao que chamamos prioridade do objeto (Adorno, 1997b), que justifica a necessidade de permitir que as vozes do objeto, sua multivocalidade, se manifestem.

Selecionamos para este artigo três categorias que condensam vários dos aspectos resultantes das observações e que permitem expressar algo da produção de conhecimentos estruturados pela educação (esportiva) do corpo no ambiente em questão.

Nomeamos a primeira categoria de Castigos, punições e sacrifícios. Ela diz respeito à forma encontrada pelos treinadores para lidar com a dinâmica de repreensão e emulação de sua equipe. A segunda categoria, batizada de Formação humana $X$ sonho de profissionalização, discorre sobre o papel das representações sobre o futebol para as crianças em contraposição à formação que a escola e o esporte prometem lhes proporcionar. A escolha da terceira categoria se deu pela presença constante dos rituais nas práticas corporais organizadas, com especial atenção, nesse caso, ao esporte. Ela foi denominada Rituais como técnica.

2. Alunos e atletas assim como professor e técnico são empregadas aqui, dado o contexto estudado, como sinônimos. 


\section{Castigos, punições e sacrificios: fórmulas de emulação da educação para a dureza}

Embora o professor da turma masculina salientasse que sua prática não podia ser denominada realmente como treinamento - no sentido que Weineck (1999) e outros estudiosos atribuem a essas práticas corporais -, pois ele não tinha controle sobre todas as variáveis que a compõem como, por exemplo, a alimentação de seus atletas, sua figura como treinador parecia ser algo familiar: aquele que é simultaneamente duro, que exige o máximo de seus atletas, mas que também pode ser condescendente e paternalista quando mais bem lhe convém em ambos os casos está suposta a heteronomia, a submissão e a menoridade dos atletas.

Foi freqüente observar o uso de técnicas de disciplinamento para validar as ações do treinador que, por sua vez, incidiam diretamente sobre o corpo e a vontade das crianças. A importância que o professor reservava à disciplina ficou explícita já no primeiro momento em que conversávamos e ele nos falava que já dissera aos seus atletas que o jogo "começaria no vestiário" e que a partir do momento que entrassem em quadra estariam proibidos de olhar para arquibancada - onde pais e mães se colocavam, como observamos, como guardiões do desempenho das crianças, fiscais do trabalho da arbitragem e linha de apoio verbal a favor da equipe dos filhos e contra o adversário. Disse ainda que felizmente ele nunca tivera problema com nenhum pai ou atleta, mas que se os alunos em casa não tinham disciplina, na quadra, seu lugar de atuação e domínio, não abriria mão disso. Para ele, seu papel como educador era o do disciplinamento dos atletas. É complexa a relação entre os processos de formação na escola e no seio da família. Apenas para tomarmos um exemplo de um grande pensador contemporâneo, vale a pena citar que Adorno (1971) defendia que a escola deveria oferecer às crianças experiências formativas que, no limite, pudessem até mesmo rivalizar com aquelas que partilham no seio familiar, freqüentemente vinculadas ao aprendizado do preconceito. 0 exemplo por nós citado se refere a uma involuntária sátira da assertiva de Adorno, ao reforçar o caráter autoritário do disciplinamento corporal.

Ao observarmos as sessões, essa disposição do professor ficou ainda mais clara, pois acompanhamos o modo como conduzia o treinamento, tendo sido ele sempre aquele que determinava as atividades, as pausas e a duração das atividades ao exigir que seus alunos abandonassem as brincadeiras e que se dedicassem ao máximo àquele momento. 0 professor fazia uso inclusive de clichês do mundo esportivo para reafirmar suas orientações que freqüentemente estavam associadas ao asceticismo do esporte. Em um dos treinos, por exemplo, ao ministrar atividades de condicionamento físico, tendo escutado reclamações e para justificar sua vontade e a atividade proposta, proferiu: "Nada se consegue sem sacrifício!" Trata-se aqui de ter presente que o esporte sugere uma pedagogia que se associa à tolerância à dor, que passa a ser um componente normal e mesmo desejado na preparação esportiva (Vaz, 1999), fenômeno que não deve ser negligenciado se considerarmos que pode ser um sintoma da consciência reificada, uma relação patogênica com o corpo, realçada pela educação pela dureza que ensina, em última instância, uma indiferença em relação à dor, a própria e àquela sentida pelos outros (Adorno, 1997b).

Um outro aspecto que emerge, talvez com mais força ainda, refere-se aos momentos em que o professor parecia necessitar de algo que o apoiasse no sentido de que as crianças percebessem a importância da disciplina e que dela fizessem uso. Isso se concretizava quando os atletas não realizavam o que era esperado ou estavam dispersos, rindo ou conversando. 0 professor então fazia uso do castigo, que se localizará diretamente sobre o corpo dos alunos, proibindo-os de beber água, de sentar quando terminada a série de exercícios proposta ou ainda exigindo a repetição de uma atividade como forma de "pagamento" pela falta de 
disciplina. Destaque-se que o uso dos castigos como ferramenta pedagógica é praxe na história da escolarização e está presente tanto na sala de aula quanto nas quadras e nos pátios. Um bom exemplo pode ser encontrado em Dalabrida (2001) que, ao discorrer sobre como a maquinaria escolar jesuítica funcionava, demonstra o constante uso dos incitamentos, da vigilância panóptica e também dos castigos, cuja função era sobretudo normalizar. Se a inspiração em Foucault (1988) é evidente, vale lembrar, então, uma passagem da Genealogia da moral, de Nietzsche (2001), ao fazer um certo catálogo de castigos:

Castigo como neutralização, como impedimento de novos danos. Castigo como pagamento de um dano ao prejudicado, sob qualquer forma (também na compensação afetiva). Castigo como isolamento da perturbação do equilíbrio, para impedir o alastramento da perturbação. Castigo como inspiração de temor àqueles que determinam e executam o castigo. Castigo como espécie de compensação pelas vantagens que o criminoso até então desfrutou [...]. Castigo como segregação de um elemento que degenera [...]. (p. 69)

Também chama a atenção como os discursos sobre o sacrifício e a dedicação eram incorporados pelos atletas. Os adolescentes entendiam como verdade o fato de que, para poderem - no duplo sentido da palavra: capacidade e também autorização - vencer, era necessário uma carga grande de treinamento, mesmo que não a desejassem ou que ficassem cansados. Vale citar a fala de um dos meninos entrevistados ao ser indagado sobre a grande ênfase dada pelo técnico ao treinamento e sobre a fadiga por treinar todos os dias da semana e jogar futebol de campo no domingo: respondeu que sim, que ficava muito cansado, que no sábado fazem físico, correm todo o campo, às vezes jogavam no domingo e na segunda havia treino novamente, mas que ele sabia que isso era bom para ele.
Essa questão ganha dois contornos relevantes. Um deles se relaciona ao fato de que o processo civilizador pode ser lido como um constante e progressivo avançar das atividades miméticas para a racionalidade (Horkheimer, 1996). Disso é expressão o esporte, uma vez que ele mesmo é, em grande medida, uma sistematização dos jogos populares estruturados no sentido da racionalização, da universalidade de formas e regras, no desempenho e na exploração máximos dos corpos. Esse pareceu ser um ideário importante para os meninos que treinavam, como se verá adiante. Um outro elemento importante é que algumas vezes os jovens aceitavam e reforçavam a idéia de que nem sempre o mais importante seria aquilo que eles prefeririam fazer no momento, diferenciando gosto de utilidade, algo também encontrado nos resultados de pesquisa de Lovisolo (1995) e Vaz, Bassani e Silva (2002).

Para as meninas, esses sacrifícios e punições ganham ainda um outro alcance. A condição originalmente masculina e secundariamente feminina do esporte ganha expressão decisiva no futsal delas, tornando-o menos prestigiado, exigindo-lhes a reafirmação constantemente de sua condição de atleta. Elas pareciam ter de sempre assegurar essa qualidade. Isso nos lembra que todo o etos esportivo é por natureza masculino e que as mulheres parecem ainda não ter alcançado força suficiente para sustentar suas práticas esportivas, ainda que freqüentemente o discurso do establishment esportivo seja outro. Essa necessidade das meninas em provarem que também sabem jogar futebol é reconhecida por elas:

Eu não agüento mais, chego em casa tarde, tenho que tomar banho, comer e caio na cama... Isso sem contar ter que agüentar os meninos. A quadra é sempre pra eles.

0 próprio técnico, como já dissemos, parecia por à prova, constantemente, a capacidade das meninas. Para estimulá-las a provar suas habilidades no futsal, fazia uso dos mes- 
mos clichês que o professor da turma masculina, mas adicionando, entretanto, a alusão à condição feminina como correspondente à menoridade na presteza esportiva: "Nós temos chance de lutar de igual pra igual com os outros times, só que isso depende de vocês e não de mim. Se vocês resolverem se preocupar com as unhas e com o celular, a gente tá arrombado!" Dizia ainda que não querer "moleza", que aquela seria a hora que elas teriam para mostrar que sabiam jogar futebol, pois "andar no shopping" sim, elas sabiam e faziam bem.

\section{Formação humana $X$ sonho de profissionalização}

Como algumas pesquisas que se dedicaram a estudar o esporte como fenômeno social para crianças e jovens demonstram (Zaluar, 1991; Bassani; Torri; Vaz, 2003; Gonçalves, 2003), fica claro o papel que a expectativa de profissionalismo exerce no imaginário, nos sonhos e nas expectativas de muitos praticantes. lsso também aconteceu, conforme verificamos na análise de nossos dados, não apenas em relação aos alunos, mas também aos pais e, de modo especial, ao técnico dos meninos.

As crianças tinham como exemplo o futebol profissional que em nosso país, de forma muito peculiar, possui importância singular, um tema talvez mais mobilizador do que a economia, a desigualdade social e a educação. Os pequenos atletas desejavam e esperavam tornarse jogadores, talvez para ganharem os prometidos milhões em moeda estrangeira e para andar em carros importados, doadores de alto prestígio social entre nós. Seus pais pareciam esperar assistir a seus filhos na televisão jogando no time pelo qual têm simpatia, vendo assim seus esforços e incentivos recompensados. Tratava-se, de certa forma, daquilo que Zaluar (1991) identificou como um investimento de toda a família na formação do jogador, algo que supostamente poderá, no futuro, gerar vantagens para todos.

Nesse contexto, o técnico do grupo masculino acompanhado exercia um papel pa- radoxal. Sua função parecia ser preparar os menores ao torná-los visíveis para despontarem no esporte. Entretanto, muitas vezes, negava-se a executar tal função, fazendo questão de advertir os meninos quanto ao exagero do sonho, do caráter enganoso que o futebol poderia ter, agindo como, talvez se possa dizer, um mestre na tradição do iluminismo a e esclarecer e desmistificar. Não raras foram as ocasiões em que se dirigiu aos atletas para expor essas preocupações, como numa fala dirigida em um momento de tensão em um dos treinos, quando a mãe de um dos atletas discutia com seu filho por considerar que a carga de treino a que ele era submetido seria exagerada - tratava-se de um menino que também jogava futebol de campo:

Não se iludam com o campo, que o campo é ilusão. Estudem porque, se é para aparecer a oportunidade, vai aparecer lá com 16, 17 anos. Aí vão estar mais maduros para escolher. Pelas minhas mãos, já passaram uns dez mil meninos e eu conto nos dedos das mãos quem chegou lá. E aí acontece de querer ajudar pai e mãe e se iludem. Estudem porque isso é certo, o resto é sonho, futebol é sonho.

Inúmeras vezes, o treinador recorreu à suposta superioridade que o futsal teria sobre o futebol de campo, contrariando, portanto, todo o ideário de sonhos brasileiro, acentuando que o primeiro seria dirigido por professor de Educação Física e o segundo por aqueles que são comumente chamados de boleiros, exatletas que desempenhariam um trabalho incompleto com as crianças.

Essa fantasia futebolística foi sempre reforçada nas crianças, mas também em seus pais, em parte, provavelmente, pela visibilidade cada vez maior que o futebol profissional de Florianópolis encontra na mídia esportiva, não somente no estado, mas em todo país, com equipes na primeira e segunda divisões nacionais. É possível que se deva também ao lugar que o futsal catarinense alcança no cenário 
nacional, contando com estrelas de grandeza internacional e jogos de seus times televisionados pelos canais esportivos de TV a cabo. A proximidade com essa cultura pode permitir que as crianças fiquem mais propensas a se deixar influenciar pelo sonho de se tornar um astro do futebol. Nesse ponto, o técnico acredita que tanto seu trabalho quanto os de outros professores que ministram aulas de futsal seriam uma prática privilegiada, pois além de ensinarem um esporte às crianças, trabalhariam com a integralidade do ser humano ${ }^{3}$. Em suas palavras:

Quem trabalha com o futsal é professor de Educação Física, com especialização, que sabe trabalhar, e lá no futebol acontece de muito ex-jogador estar dando treino. Jogar no Canto do Rio [tradicional equipe do futebol amador de Florianópolis] no sábado, no domingo, não tem problema. Mas eu conheço o trabalho de base do Avaí, por exemplo, e sei que não tem qualidade, eles só matam os guris fazendo eles correrem pela praia e dando treino forte. Não é nem para falar do trabalho dos outros, mas é que geralmente acontece de colocarem sonhos loucos na cabeça de vocês.

Esse discurso é apoiado pelos pais, também de forma paradoxal, pois com sua constante presença nos treinos e nas competições, suas discussões com os árbitros, seu freqüente apoio por vezes financeiro para que a equipe tomasse parte dos campeonatos, demonstravam interesse concreto no sucesso esportivo, atual e talvez futuro, dos filhos. Entretanto, seus discursos acompanhavam as assertivas do professor ao dizerem respeito ao aspecto de formação total pelo esporte, como nessa fala do pai de um aluno: "não tem que pensar só no futebol e sim como gente, como ser humano, porque se no jogo trata os outros na porrada, na vida vai tratar os outros assim também." Destaque-se que esse tipo de discurso também está presente nos programas de governo que promovem o esporte como meio de socializa- ção de crianças e jovens (Bracht; Almeida, 2003). Na verdade, em que pese todas as críticas que o esporte tradicional sofreu e sofre como modelo de educação do corpo e do movimento (Taborda de Oliveira, 2000; Vaz, 1999; Kunz, 1989; entre outros), continua a crença em seu poder civilizador, regenerador, de inclusão social (Bassani; Torri; Vaz, 2003).

As meninas não ficam alheias ao sonho de profissionalização por meio do esporte, entretanto, em função do futebol feminino ainda possuir pouca visibilidade na mídia nacional - embora cada vez mais venha aparecendo com a medalha olímpica da seleção de futebol em 2004, o recente ouro nos Jogos Pan-americanos do Rio de Janeiro e, principalmente, por Santa Catarina possuir atualmente as equipes campeã e vice-campeã adultas de futsal - esse peso para elas aparece de forma diferente. Sonham em se profissionalizar, mas têm antes de provar a todos que sabem jogar bola.

A presença contemporânea das mulheres no esporte é fruto ou conquista de um longo processo histórico, algo ainda mais complexo quando se pensa no futebol. Se sua prática é hoje mais aceita, talvez seja vítima de um outro tipo de preconceito, do que aquele comumente relacionado a sua suposta menor habilidade técnica. Referimo-nos aqui à discussão sobre sua feminilidade, por vezes posta em prova nas atividades esportivas. Para os homens, qualidades como ser macho, forte, vigoroso são naturalmente explicitadas e confirmadas pelo esporte. Rial (1998) mostra como o rúgbi e o judô são práticas que aceleram, do ponto de vista de gênero, a confirmação de características tidas como eminentemente masculinas, como a resistência à dor e o reconhecimento da virilidade pelos pares homens e pelas mulheres. As pesqui-

3. 0 discurso de formação integral do ser humano é utilizado muitas vezes pela Educação Física, e também por outras disciplinas, para legitimar sua atuação numa perspectiva pedagógica progressista ou crítica contrária à idéia inicial de que a Educação Física preocupar-se-ia somente com o corpo físico e orgânico.

4. Refere-se ao Avaí Futebol Clube, agremiação tradicional do futebol catarinense, várias vezes campeã do estado de Santa Catarina e atualmente na segunda divisão do futebol brasileiro. 
sas de Wacquant (2002), Cecchetto (2004) e Turelli e Vaz (2006) mostram como a masculinidade se acentua como reafirmação nas lutas. $\mathrm{Na}$ literatura brasileira, encontramos um tratamento exemplar da temática no livro Perseguição e cerco a Juvêncio Gutierrez, de Tabajara Ruas (1992) e no conto de Cintia Moscovich (2002). As mulheres, no entanto - "Vocês estão parecendo umas moças jogando", diz-se aos rapazes, como a confirmar os estereótipos de gênero -, têm de constantemente provar que não perdem sua feminilidade praticando esporte. Essa feminilidade é aquela que associa as mulheres com a proximidade do curso que leva à maternidade, à docilidade, enfim, à condição de objeto da natureza e, portanto, passível de ser dominada.

As atletas pesquisadas parecem não sofrer tanta influência dos pais, diferentemente dos meninos, que tinham seus treinos observados pelos seus maiores. Estas, talvez por serem mais crescidas - e porque a prática esportiva certamente não se coloca com tanta força como opção de profissionalização ${ }^{5}$-, não eram acompanhadas de perto. Entretanto, nos momentos dos jogos oficiais, os pais se faziam presentes e de forma enfática participavam da partida, não apenas torcendo, mas até mesmo chorando ou discutindo com as filhas, com os técnicos adversários e com os árbitros, da mesma forma que os pais dos meninos ou ainda como a imprensa esportiva apresenta o comportamento das torcidas como show de exacerbação pessoal e coletiva.

Adelman (2003), em estudo com mulheres atletas de voleibol e de equitação, considera que o esporte é hoje "um dos mais importantes espaços de conflitos relativos à definição da corporalidade feminina" (p. 449). Se por um lado o esporte possibilita à mulher a idéia da igualdade de gênero, a possibilidade em realizar a mesma prática esportiva que o homem, de transgressão da idéia de corpo frágil, por outro, o esporte talvez a enquadre em um outro tipo de controle: aquele que outorga ao corpo das atletas um novo modelo de feminilidade. Corpo que deve ser saudável, atlético, ativo, firme, mas não com músculos demais. Ele tem de ser construído por meio de dietas e exercícios intensivos e segundo padrões de beleza que se aproximam daqueles predicados e perseguidos em academias de ginástica e musculação (Sabino, 2000; Hansen; Vaz, 2006).

Apoiada em Susan Bordo, Adelman (2003) sugere que no esporte haveria uma estética da limitação: "A feminilidade é construída através da aceitação de restrições, da limitação, da visão, ou da escolha de uma rota indireta" (p. 451). Como expressão de resistência, pela simples prática, mas também pela profissionalização, o esporte poderia representar uma empowered femininity (Adelman, 2003) a transgredir essa estética da limitação, ainda que também a possibilidade de um incremento à adaptação à feminilidade normativa e aos atuais padrões da cultura do corpo feminino, tão extensamente difundidos pelos veículos porta-vozes dos esquemas da indústria cultural: televisão, revistas ilustradas femininas, cadernos femininos de jornais, entre tantos outros.

Verificou-se no campo estudado a confirmação de uma certa estética da limitação, uma vez que o padrão de sucesso técnico e estético do jogo das meninas se refere ao masculino, tomado como modelo a ser seguido e, por isso, ganha ares problemáticos "jogar como moças" e torna-se um elogio ao feminino "jogar como homem" ou "lutar como homem", como destacam Turelli e Vaz (2006). Isso em nada difere do curso geral da esportivização do feminino: é considerada uma conquista a prática de esportes e eventos em modalidades consideradas masculinas, como o futebol, o boxe e o lançamento de martelo no atletismo, práticas antes vedadas às mulheres, mas não se admite a possibilidade de meninos praticarem ginástica rítmica ou nado sincronizado, esportes historicamente femininos.

\section{Rituais como técnica}

0 trabalho dos dois técnicos pouco se diferenciava de uma imagem mimetizada da-

5. Zaluar (1991) mostra como a expectativa de profissionalização por parte de freqüentadores de programas sociais com práticas esportivas é eminentemente dos meninos. 
quele realizado pelos seus congêneres do futebol de campo profissional. 0 treinamento acontece nos esportes de alta competição para aumentar e potencializar o desempenho. Dele faz parte o registro moral do esforço como movimento socialmente positivo para a formação humana. Nos treinamentos observados, não foi diferente. Pelo contrário, professores/técnicos constantemente se dirigiam aos seus alunos para reafirmar o papel pedagógico positivo do esforço requerido.

As atividades observadas eram quase sempre muito parecidas, chegando inclusive a não se diferenciar em nada de uma sessão de treino a outra. Percebemos, no entanto, que o discurso do professor mudava dependendo do momento em que o grupo se encontrava, o que sugere a força do ritual como suporte para discursos de adequação. Ora o treinamento procurava prepará-los fisicamente, ora deveria servir para manter o padrão de jogo da equipe. Contudo, as atividades propostas eram as mesmas em ambas situações.

A pouca variada dinâmica se constituía de atividades de alongamento muscular, corrida de aquecimento, procedimentos técnicos e o chamado coletivo, que é a simulação de um jogo propriamente dito. Quando da iminência de alguma partida pelos campeonatos do qual participava a equipe, as atividades técnicas ganhavam mais espaço.

Os alunos reclamavam muito das atividades recorrentes, entretanto continuavam a repeti-las porque sabiam que como recompensa no final das séries haveria o coletivo, uma atividade-fim que coincidia com os objetivos de propriamente jogar futsal. Caso o esperado não acontecesse, o professor era alvo de reclamações, mas com ar de quem sabia o que estava fazendo, as ignorava.

Isso nos leva a observar que tais atividades não teriam importância para o desempenho dos atletas se levadas em consideração as premissas do treinamento no que diz respeito, por exemplo, à supercompensação - a relação entre estímulo e descanso necessária para a ob- tenção da forma física - e à periodicidade organização da estimulação corporal conforme o tempo disponível para o treinamento -, princípios básicos constituintes da teoria do treinamento desportivo (Weineck, 1999). As atividades possuíam, entretanto, um valor ritualístico, que muitas vezes servia ao professor para validar seu trabalho frente aos pais e aos próprios alunos, já que talvez ele soubesse, ou ao menos intuísse, que certas atividades seriam desnecessárias. É importante notar que os rituais exercem um papel aglutinador importante no esporte, ele mesmo sendo uma grande atividade ritualística.

Em outras ocasiões, os próprios alunos questionavam a legitimidade das atividades, não somente pela falta do coletivo, mas também quando se tratava de outras práticas. Isso ficou claro por ocasião de um treinamento no dia anterior a uma partida pelo campeonato estadual. Nele o professor os fazia aquecer com muitas voltas pela quadra e um dos alunos questionou em voz baixa a legitimidade do exercício: "Tem estadual amanhã, do que adianta a gente correr isso hoje?" É curioso verificar que a função exercida pouco tinha a ver com o objetivo facilmente identificável do treinamento, a preparação para a competição. Parece ser que está muito mais envolvida aí a crítica de Adorno (1997b) à crença de que uma educação para a severidade traria benefícios pedagógicos. Essa educação proporia o aprendizado de ser duro consigo mesmo, intolerante à própria dor, para também o ser com os outros e, final das contas, ser indiferente ao sofrimento em geral, estando associada à consciência reificada. Esse parece ser um elemento importante na constituição da lógica da pedagogia esportiva, sempre vinculada ao fascínio pela maximização e pelos exemplos de superação dos limites e da dor.

0 aparente paradoxo ainda mais bem se coloca se considerarmos que os alunos, por já treinarem há muito tempo, reconheciam que atividades de preparação física antes de uma partida pouco ou nada têm de relevante, senão 
para aumentar o cansaço. Esses elementos pedagógicos não são, no entanto, unidirecionais, uma vez que, em outra ocasião, também estando os atletas a um dia de uma partida, o próprio professor pediu a eles que não corressem ou não se cansassem muito.

\section{Considerações finais}

Algumas questões permanecem em aberto. Seria necessário, por exemplo, estudar com mais profundidade como os atletas interpretam o possível caráter funcional de uma atividade que não tem valor preparatório para a competição, mas que pode ser reconhecida como importante para um certo tipo de (de)formação. Está em jogo aí a relação entre as atividades rituais que atualizam uma certa tradição da pedagogia esportiva e o caráter pretensamente científico do treinamento, ambos vinculados, no entanto, aos mesmos mecanismos de controle do corpo. As categorias articuladoras sugerem a idéia de que o corpo na escola, por meio das práticas esportivas, é um forte elemento definidor de condutas e de comportamentos.

Nossos resultados indicam ainda uma inter-relação estreita entre as três categorias desenvolvidas. Os rituais, fundamentalmente atualizadores de uma tradição, conformam as expectativas para um possível futuro profissional vislumbrado no futebol-espetáculo profissional e ambos emolduram um imaginário que considera o esporte um poderoso dispositivo de formação que legitima e justifica o sacrifício, algo ainda hoje inquestionável pelo discurso espraiado na dinâmica da indústria cultural e confirmado pelos atores investigados por nós.

Os resultados demonstram ainda, como havíamos sugerido, a centralidade do corpo como elemento fundamental para pensarmos a educação das crianças nas escolas. 0 esporte como signo civilizador potencializa esse mosai- co de preocupações com o corpo, que parecem configurar, juntamente com outros projetos, uma possível pedagogia do corpo na sociedade contemporânea.

Se não é novidade a brutal hegemonia do esporte como tema de ensino nas aulas de Educação Física, freqüentemente trabalhado como modalidade única, o futebol - ou, como indicaram Vaz, Bassani e Silva (2002), como uma paródia do esporte, dada a falta de condições técnicas e materiais para que ele seja de fato reproduzido na escola - agrava se pensarmos que as aulas de Educação Física, uma disciplina do conhecimento, de ensino obrigatório nas escolas e com amplo espectro possível de conteúdos, é substituída pela prática da competição e pela monocultura esportiva.

Essa substituição das aulas de Educação Física por outras práticas e com outros sentidos que não o da formação escolar faz eclipsar a preocupação formativa da escolarização, reduzindo o ensino dos esportes à mera prática e reforçando dois dos impasses que as aulas de Educação Física enfrentam: 1) transforma a riqueza de elementos culturais importantes como o esporte em práticas de adestramento corporal, celebração da dor e fomento de preconceitos diversos, inclusive de gênero; 2) reproduz a idéia de que o esporte praticado com fins competitivos é superior àquele das aulas de Educação Física, uma vez que nessa última o conteúdo é esvaziado em favor da mera ocupação do tempo, conforme os próprios alunos afirmam.

Por fim, vale destacar a importância da indústria cultural nos processos de conformação das práticas esportivas no ambiente estudado: normas, expectativas, vocabulário e práticas estão fortemente referenciadas no esporte-espetáculo, tal como o conhecemos por meio da indústria do entretenimento que não apenas o divulga, mas o desenvolve como produto largamente consumido até mesmo nas práticas escolares. 


\section{Referências bibliográficas}

ADELMAN, M. Mulheres atletas: re-significações da corporalidade feminina. Estudos Feministas. Florianópolis, v. 11, n 2, p. 445 465, julho/dezembro de 2003.

ADORNO, T. W. Zur Bekämpfung des Antisemitismus heute. In: Kritik: kleine Schriften zur Gesellschaft. Frankfurt am Main: Suhrkamp, 1971, p. 105-133. Negative Dialektik. In: Gesammelte Schriften 6. Frankfurt am Main: Suhrkamp, 1997. Das Schema der Massenkultur. In: Gesammelte Schriften 3. Frankfurt am Main: Suhrkamp, 1997a. Erziehung nach Auschwitz. In: Gesammelte Schriften 10-2. Frankfurt am Main: Suhrkamp, 1997b.

BASSANI, J. J.; TORRI, D.; VAZ, A. F. Sobre a presença do esporte na escola: paradoxos e ambigüidades. Movimento. Porto Alegre, v. 9, n. 2, p. 89-112, maio/agosto de 2003.

BRACHT, V.; ALMEIDA, F. Q. A política de esporte escolar no Brasil: a pseudovalorização da Educação Física. Revista brasileira de ciências do esporte. Campinas, v. 24, n. 3, p. 87-101, maio 2003.

CECCHETTO, F. R. Violência e estilos de masculinidade. Rio de Janeiro: Editora FGV, 2004.

DALABRIDA, N. A fabricação escolar das elites: 0 Ginásio Catarinense na Primeira República. Florianópolis: Cidade Futura, 2001.

FOUCAULT, M. Vigiar e punir: história das prisões. Petrópolis: Vozes, 1988.

GONÇALVES, M. A. R. A vila olímpica da verde-e-rosa. Rio de Janeiro: FGV, 2003.

HANSEN, Roger, VAZ, A. F. "Sarados" e "gostosas" entre alguns outros: aspectos da educação de corpos masculinos e femininos em academias de ginástica e musculação. Movimento. Porto Alegre, v. 12, p.133-152, 2006.

HORKHEIMER, M. Eclipse of reason. New York: Continuum, 1996.

HORKHEIMER, M.; ADORNO, T. W. Dialektik der Afklärung: philosophische Fragmente. In: ADORNO, T. W. Gesammelte Schriften 3. Frankfurt am Main: Suhrkamp, 1997a.

KUNZ, E. 0 esporte enquanto fator determinante na Educação Física. Contexto e Educação, ljuí, ano IV, n. 15, 1989. p. 63-73.

LOVISOLO, H. A Educação Física como arte da mediação. Rio de Janeiro: Sprint, 1995.

MOSCOVICH, C. Sheine meidale. In: 0 reino das cebolas: contos e narrativas. Porto Alegre: L\&PM, 2002, p. 48-65.

NIETZSCHE, F. Genealogia da moral. Uma polêmica. São Paulo: Companhia das Letras, 2001.

RIAL, C. S. M. Rúgbi e judô: esporte e masculinidade. In: PEDRO, M. J.; GROSSI, M. P. Masculino, feminino, plural: gênero na interdisciplinariedade. Florianópolis: Ed. Mulheres, 1998. p. 229-258.

RUAS, T. Perseguição e cerco a Juvêncio Gutierrez. Porto Alegre: L\&PM, 1992.

SABINO, C. Musculação: expansão e manutenção da masculinidade. In: GOLDENBERG, M. (Org.). Os novos desejos: das academias às agências de encontro. Rio de Janeiro: Record, 2000. p. 61-103.

TABORDA DE OLIVEIRA, M. Educação Física escolar: formação ou pseudoformação. Educar em Revista. Curitiba, n. 16, 2000, p. $11-26$.

VAZ, A. F. Treinar o corpo, dominar a natureza: notas para uma análise do esporte com base no treinamento corporal. Cadernos CEDES. Campinas, ano XIX, n. 48, ago. 1999. p. 89-106. 
VAZ, A. F.; BASSANI, J. J. ; SILVA, A. S. Identidades e rituais na educação do corpo na escola: um estudo em aulas de Educação Física no ensino fundamental. Motus Corporis. Rio de Janeiro, v. 9, n. 2, p. 23-39, 2002.

WACQUANT, Loïc. Corpo e alma: notas etnográficas de um aprendiz de boxe. Tradução de Angela Ramalho. Rio de Janeiro: Relume Dumará, 2002.

WEINECK, J. Treinamento ideal. São Paulo: Manole, 1999.

WELSCH, W. Esporte - visto esteticamente e mesmo como arte? In: ROSENFIELD, D. L. Ética e estética. Rio de Janeiro: Jorge Zahar, 2001. p. 142-165.

ZALUAR, A. M. 0 esporte na educação e na política pública. Educação e Sociedade. Campinas, n. 38, p 19-45, abril/1991.

Recebido em 09.09.05

Aprovado em 29.08.07

Danielle Torri, ex-bolsista PIBIC/CNPq/UFSC, licenciada em Educação Física, mestranda pelo Programa de Pós-graduação em Educação da UFSC e bolsista da CAPES, é professora substituta do Departamento de Metodologia de Ensino da UFSC.

Beatriz Staimbach Albino, ex-bolsista PIBIC/CNPq/UFSC, licenciada em Educação Física, é mestranda pelo Programa de Pós-graduação em Educação Física da UFSC.

Alexandre Fernandez Vaz, doutor pela Universidade de Hannover, é professor do Programas de Pós-Graduação em Educação e Educação Física da UFSC e pesquisador CNPq (Nível 2 - Fundamentos da Educação). 